\title{
An application of RFID in supply chain management to reduce inventory estimation error
}

\author{
Hamed Raki*
}

Department of Industrial Engineering, South Tehran Branch, Islamic Azad University, Tehran, Iran

\begin{tabular}{l}
\hline C H R O N I C L E \\
\hline Article history: \\
Received September 10, 2013 \\
Received in revised format \\
10 December 2013 \\
Accepted January 122014 \\
Available online \\
January 182014 \\
\hline Keywords: \\
SCM \\
RFID \\
Auto industry
\end{tabular}
A B S T R A C T

\begin{abstract}
Radio-frequency identification (RFID) is the wireless non-contact implementation of radiofrequency electromagnetic fields to transfer necessary data to identify and to track tags attached to objects, automatically. RFID has been successfully used for supply chain management (SCM) problems in order to reduce errors associated with inventory. This paper uses RFID technique in five different scenarios of labeling, errors in stolen parts, waste, wrong replacement and delivery. The study uses simulation technique based on Enterprise Dynamics to analyze three parts in an auto industry. The study considers different criteria including inventory error estimation, profitability, profitability, customer satisfaction and SCM performance. The preliminary results indicate that the proposed method is capable of optimizing most objectives, significantly.
\end{abstract}

\section{Introduction}

Radio-frequency identification (RFID) is the wireless non-contact implementation of radio-frequency electromagnetic fields to transfer necessary data to identify and to track tags attached to objects, automatically (Asif \& Mandviwalla, 2005; Niederman et al., 2007). RFID has been successfully used for supply chain management (SCM) problems in order to reduce errors associated with inventory. RFID technologies hold the promise of closing some necessary information gaps in the supply chain, more specifically in retailing and logistics. As a mobile technology, RFID is able to enable "process freedoms" and real-time visibility into supply chains (Angeles, 2005). Gaukler et al. (2007) considered a supply chain with one manufacturer and one retailer and within the context of this retail supply chain, they presented analytic models of the advantages of item-level RFID to both supply chain partners. They examined both the case of a dominant manufacturer as well as the case of a dominant retailer, and investigated the results of an introduction of item-level RFID to such a supply chain based on market power characteristics. Under each scenario, they demonstrated how the expenses of item-level RFID could be allocated among supply chain partners such that supply chain profit would be optimized.

* Corresponding author. Tel.: +98 9393303130

E-mail addresses: saho84@rocketmail.com (H. Raki)

(C) 2014 Growing Science Ltd. All rights reserved. doi: $10.5267 /$ j.uscm.2014.1.001 
Cannon et al. (2008) aimed to point to established theory bases from other disciplines applied to show the advantages, complexities and risks accompanying the adoption of RFID technology. They presented different theoretical disciplines to describe tension between uncertainty that spurs RFID adoption and uncertainty that accompanies RFID adoption.

Prater et al. (2005) investigated market drivers that are leading to RFID application in the grocery industry and provided a theoretical framework for future applied research on RFID implementation. They also developed a research framework, which includes research using modeling techniques, RFID implementation and the effect of RFID on daily operational issues.

Veronneau and Roy (2009) explored the potential contribution of RFID and other technologies to the efficiency of a cruise corporation's service supply chain. They also investigated different processes required in that supply chain. They reported that RFID could not reach direct gains significant enough on a pallet-level-tagging deployment to meet the expenses. However, a case-level-tagging deployment might be possible under certain conditions. They also demonstrated that contrary to current beliefs in the literature, density of flow of goods and not the scale of operations, detects whether a good return on investment is achievable.

\section{The proposed study}

This paper uses RFID technique in five different scenarios of labeling, errors in stolen parts, waste, wrong replacement and delivery. The study uses simulation technique based on Enterprise Dynamics to analyze three parts in an auto industry. The study considers different criteria including inventory error estimation, profitability, profitability, customer satisfaction and SCM performance. The proposed study has been applied for the body of a vehicle produced in Iran called Pride and the production line is composed of 34 workstations. The work stations are located longitudinally in one direction. Three major parts with consistent order times are considered for the proposed case study. The order policy is as follows: At the end of each shift operators attempt to count the number of existing items from the shop and warehouse. Next, the production planning is accomplished based on throughput of the next shift, which are production of 150 items. Next, manager attempts to issue a draft order for the storage and transportation of the units into production facilities. The scheduling for shipping parts to a spare workstation is based on times for transportation performed by trucks, received orders, counting and issuing orders and delays in storage and in transportation. To determine the time required for each stage, the action was sampled in three shifts based on stop-watch system. Table 1 shows the summary of our computations.

Table 1

The summary of times required to accomplish different tasks

\begin{tabular}{ccccccc}
\hline $\begin{array}{c}\text { Part } \\
\text { number }\end{array}$ & $\begin{array}{c}\text { Maximum lift truck } \\
\text { time in minutes }\end{array}$ & $\begin{array}{c}\text { Maximum } \\
\text { lead time }\end{array}$ & $\begin{array}{c}\text { Issuing } \\
\text { orders }\end{array}$ & $\begin{array}{c}\text { Delay in } \\
\text { storage }\end{array}$ & $\begin{array}{c}\text { Delay in } \\
\text { transportation }\end{array}$ & $\begin{array}{c}\text { Total } \\
\text { time }\end{array}$ \\
\hline 1 & 6 & 60 & 65 & 6 & 46.6 & 183.6 \\
2 & 6 & 60 & 65 & 6 & 46.6 & 183.6 \\
3 & 6 & 60 & 65 & 6 & 46.6 & 183.6 \\
\hline
\end{tabular}

Let $T$ be the shift time and $N$ be the number of production, then the cycle time $(C)$ is calculated as $C$ $=T / N$. Therefore, rate of production (ROP) is calculated as follows,

ROP $=$ daily demand $\times$ waiting time (days) + safety stock - order in process. In addition, economic order quantity (EOQ) is calculated as follows, 
$\mathrm{Q}^{*}=\mathrm{EOQ}=\sqrt{\frac{2 a D}{C h}}$

where $a$ is the ordering cost, $D$ represents demand and $C_{h}$ states the holding cost. The case study of this paper produces 700 units per day in three shifts of 240, 240 and 220 and there are 30 workstations. In production planning, first, the body of the vehicle is entered into the production unit and then different parts are assembled on the body. Each car is assembled in 120 seconds in the first and the second shifts and 131 seconds in the third shift. We study the behavior of the system under three different circumstances, one for $4^{\text {th }}$ hour, one for $6^{\text {th }}$ hour and the last one for $8^{\text {th }}$ hour. In addition, we consider three scenarios for the beginning inventory where the first one considers the level of inventory is less than demand, equal and more than demand. The other point is that for $4^{\text {th }}$ hour we only consider the production for the same shift, while for $6^{\text {th }}$ and $8^{\text {th }}$ hours we consider the production for the same and the next shift. Therefore, there are 9 different scenarios associated with the proposed study of this paper.

The first scenario considers the circumstance where we are in $4^{\text {th }}$ hour of shift, inventory exceeds demand in that shift, and we have 183.6 minutes to complete all productions. Table 1 demonstrates the summary of information for all nine different scenarios.

\section{Table 1}

The summary of the production and inventory in all nine scenarios

\begin{tabular}{|c|c|c|c|c|c|}
\hline Scenario & Part & Initial inventory & Entry production rate & Parts in process & Remained inventory \\
\hline \multirow{3}{*}{1} & 1 & 375 & 120 & 0 & 255 \\
\hline & 2 & 375 & 120 & 0 & 255 \\
\hline & 3 & 375 & 120 & 1 & 256 \\
\hline \multirow{3}{*}{2} & 1 & 240 & 120 & 0 & 120 \\
\hline & 2 & 240 & 120 & 0 & 120 \\
\hline & 3 & 240 & 120 & 1 & 121 \\
\hline \multirow{3}{*}{3} & 1 & 200 & 120 & 0 & 80 \\
\hline & 2 & 200 & 120 & 0 & 80 \\
\hline & 3 & 200 & 120 & 1 & 81 \\
\hline \multirow{3}{*}{4} & 1 & 375 & 180 & 0 & 195 \\
\hline & 2 & 375 & 180 & 0 & 195 \\
\hline & 3 & 375 & 180 & 1 & 195 \\
\hline \multirow{3}{*}{5} & 1 & 240 & 180 & 0 & 60 \\
\hline & 2 & 240 & 180 & 0 & 60 \\
\hline & 3 & 240 & 180 & 1 & 61 \\
\hline \multirow{3}{*}{6} & 1 & 200 & 180 & 0 & 20 \\
\hline & 2 & 200 & 180 & 0 & 20 \\
\hline & 3 & 200 & 180 & 1 & 21 \\
\hline \multirow{3}{*}{7} & 1 & 375 & 240 & 0 & 125 \\
\hline & 2 & 375 & 240 & 0 & 125 \\
\hline & 3 & 375 & 240 & 1 & 126 \\
\hline
\end{tabular}

In addition, Table 2 and Table 3 show the amount of consumption as well as the amount of inventory during the $6^{\text {th }}$ hour and .

Table 2

The summary of ordering at $4^{\text {th }}$ hour when production continues for 8 hours

\begin{tabular}{cccccc}
\hline \multirow{2}{*}{ Part number } & $\begin{array}{c}\text { Inventory at the } \\
\text { beginning period }\end{array}$ & $\begin{array}{c}\text { Inventory at } 4^{\text {th }} \\
\text { hour }\end{array}$ & $\begin{array}{c}\text { Inventory level up to } \\
\text { request time }\end{array}$ & $\begin{array}{c}\text { Consumption at } 8^{\text {th }} \\
\text { hour }\end{array}$ & $\begin{array}{c}\text { Inventory at } 8^{\text {th }} \\
\text { hour }\end{array}$ \\
\hline 1 & 240 & 120 & 28 & 240 & 240 \\
2 & 240 & 120 & 28 & 240 & 240 \\
3 & 240 & 120 & 29 & 239 & 240 \\
\hline
\end{tabular}


Table 3

The summary of ordering at $6^{\text {th }}$ hour when production continues for 8 hours

\begin{tabular}{cccccc}
\hline Part number & $\begin{array}{c}\text { Inventory at the } \\
\text { beginning period }\end{array}$ & $\begin{array}{c}\text { Inventory at } 6^{\text {th }} \\
\text { hour }\end{array}$ & $\begin{array}{c}\text { Inventory level up to } \\
\text { request time }\end{array}$ & $\begin{array}{c}\text { Consumption at } 8^{\text {th }} \\
\text { hour }\end{array}$ & $\begin{array}{c}\text { Inventory at } 8^{\text {th }} \\
\text { hour }\end{array}$ \\
\hline 1 & 200 & 20 & 103 & 240 & 135 \\
2 & 200 & 20 & 103 & 240 & 135 \\
3 & 200 & 21 & 104 & 239 & 136 \\
\hline
\end{tabular}

Now, we consider the production planning based on the following criteria,

1. Reviewing the number of parts in storage and workstation using RFID method,

2. Determining the period of supplying parts,

3. Entering all orders into ordering system and determining the optimal order quantity.

Based on the above assumption, we first consider the amount of order until the receipt of the next shipment at $4^{\text {th }}$ hour when the amount of inventory exceeds demand and then we consider other conditions for the $4^{\text {th }}$ hour and Table 4 shows details of our survey.

Table 4

The amount of order under various scenarios at $4^{\text {th }}$ hour

The first scenario: The amount of order until the receipt of the next shipment at $4^{\text {th }}$ hour when the amount of inventory exceeds demand

\begin{tabular}{|c|c|c|c|c|c|c|c|c|}
\hline Part & Minimum inventory & Order point & Production & Available parts & Demand & The order pallet & Order quantity & Need \\
\hline 1 & 60 & 92 & 92 & 245 & 184 & 0 & 0 & No \\
\hline 2 & 60 & 92 & 92 & 245 & 184 & 0 & 0 & NO \\
\hline 3 & 60 & 92 & 92 & 246 & 184 & 0 & 0 & NO \\
\hline \multicolumn{9}{|c|}{ The second scenario: The amount of order of a complete shift at $4^{\text {th }}$ hour when the amount of inventory exceeds demand } \\
\hline Part & Minimum inventory & Order point & Production & Available parts & Demand & The order pallet & Order quantity & Need \\
\hline 1 & 60 & 92 & 240 & 245 & 332 & 77 & 77 & YES \\
\hline 2 & 60 & 92 & 240 & 245 & 332 & 77 & 77 & YES \\
\hline 3 & 60 & 92 & 240 & 246 & 332 & 76 & 76 & YES \\
\hline
\end{tabular}

The third scenario: The amount of order until the receipt of the next shipment at $4^{\text {th }}$ hour when the amount of inventory is equal to

\begin{tabular}{llllllll}
\hline Part & Minimum inventory & Order point & Production & Available parts & Demand & The order pallet & Order quantity Need
\end{tabular}

\begin{tabular}{cccccccccc}
\hline 1 & 60 & 92 & 92 & 120 & 184 & 64 & 64 & YES \\
2 & 60 & 92 & 92 & 120 & 184 & 64 & 64 & YES \\
3 & 60 & 92 & 92 & 121 & 184 & 63 & YES \\
\hline \multicolumn{6}{l}{ The fourth scenario: The amount of order of a complete shift at $4^{\text {th }}$ hour when the amount of inventory is equal to demand } \\
\hline \multicolumn{2}{l}{ Part } & Minimum inventory & Order point & Production & Available parts & Demand & The order pallet & Order quantity & Need \\
\hline 1 & 60 & 92 & 240 & 120 & 332 & 212 & 212 & YES \\
2 & 60 & 92 & 240 & 120 & 332 & 212 & 212 & YES \\
3 & 60 & 92 & 240 & 121 & 332 & 211 & 211 & YES
\end{tabular}

The fifth scenario: The amount of order until the receipt of the next shipment at $4^{\text {th }}$ hour when the amount of inventory is less than

\begin{tabular}{cccccccc}
\hline Part & Minimum inventory & Order point & Production & Available parts & Demand & The order pallet & Order quantity \\
\hline
\end{tabular}

\begin{tabular}{ccccccccc}
\hline 1 & 60 & 92 & 240 & 80 & 332 & 252 & 252 & YES \\
2 & 60 & 92 & 240 & 80 & 332 & 252 & 252 & YES \\
3 & 60 & 92 & 240 & 81 & 332 & 251 & 251 & YES \\
\hline \multicolumn{7}{l}{ The sixth scenario: The amount of order of a complete shift at $4^{\text {th }}$ hour when the amount of inventory is less than demand } \\
\hline Part & Minimum inventory & Order point & Production & Available parts & Demand & The order pallet & Order quantity & Need \\
\hline 1 & 60 & 92 & 92 & 80 & 184 & 104 & 104 & YES \\
2 & 60 & 92 & 92 & 80 & 184 & 104 & 104 & YES \\
3 & 60 & 92 & 92 & 81 & 184 & 103 & 103 & YES \\
\hline
\end{tabular}

Similarly, we have performed the computations for the $6^{\text {th }}$ hour and Table 5 shows the results of our survey. 
Table 5

The amount of order under various scenarios at $6^{\text {th }}$ hour

\begin{tabular}{|c|c|c|c|c|c|c|c|c|}
\hline Part & Minimum inventory & Order point & Production & Available parts & Demand & The order pallet & Order quantity & Need \\
\hline 1 & 60 & 92 & 240 & 195 & 332 & 137 & 137 & YES \\
\hline 2 & 60 & 92 & 240 & 195 & 332 & 137 & 137 & YES \\
\hline 3 & 60 & 92 & 240 & 196 & 332 & 136 & 136 & YES \\
\hline \multicolumn{9}{|c|}{ The second scenario: The amount of order of a complete shift at $6^{\text {th }}$ hour when the amount of inventory exceeds demand } \\
\hline Part & Minimum inventory & Order point & Production & Available parts & Demand & The order pallet & Order quantity & Need \\
\hline 1 & 60 & 92 & 92 & 195 & 184 & 0 & 0 & $\mathrm{NO}$ \\
\hline 2 & 60 & 92 & 92 & 195 & 184 & 0 & 0 & NO \\
\hline 3 & 60 & 92 & 92 & 196 & 184 & 0 & 0 & NO \\
\hline \multicolumn{9}{|c|}{ The third scenario: The amount of order until the receipt of the next shipment at $6^{\text {th }}$ hour when the amount of inventory is equal to demand } \\
\hline Part & Minimum inventory & Order point & Production & Available parts & Demand & The order pallet & Order quantity & Need \\
\hline 1 & 60 & 92 & 92 & 60 & 184 & 124 & 124 & YES \\
\hline 2 & 60 & 92 & 92 & 60 & 184 & 124 & 124 & YES \\
\hline 3 & 60 & 92 & 92 & 61 & 184 & 123 & 123 & YES \\
\hline \multicolumn{9}{|c|}{ The fourth scenario: The amount of order of a complete shift at $6^{\text {th }}$ hour when the amount of inventory is equal to demand } \\
\hline Part & Minimum inventory & Order point & Production & Available parts & Demand & The order pallet & Order quantity & Need \\
\hline 1 & 60 & 92 & 240 & 60 & 332 & 272 & 272 & YES \\
\hline 2 & 60 & 92 & 240 & 60 & 332 & 272 & 272 & YES \\
\hline 3 & 60 & 92 & 240 & 61 & 332 & 271 & 271 & YES \\
\hline \multicolumn{9}{|c|}{ The fifth scenario: The amount of order until the receipt of the next shipment at $6^{\text {th }}$ hour when the amount of inventory is less than demand } \\
\hline Part & Minimum inventory & Order point & Production & Available parts & Demand & The order pallet & Order quantity & Need \\
\hline 1 & 60 & 92 & 92 & 20 & 184 & 164 & 164 & YES \\
\hline 2 & 60 & 92 & 92 & 20 & 184 & 164 & 164 & YES \\
\hline 3 & 60 & 92 & 92 & 21 & 184 & 163 & 163 & YES \\
\hline \multicolumn{9}{|c|}{ The sixth scenario: The amount of order of a complete shift at $6^{\text {th }}$ hour when the amount of inventory is less than demand } \\
\hline Part & Minimum inventory & Order point & Production & Available parts & Demand & The order pallet & Order quantity & Need \\
\hline 1 & 60 & 92 & 240 & 20 & 332 & 312 & 312 & YES \\
\hline 2 & 60 & 92 & 240 & 20 & 332 & 312 & 312 & YES \\
\hline 3 & 60 & 92 & 240 & 21 & 332 & 311 & 311 & YES \\
\hline
\end{tabular}

Similarly, we have performed the computations for the $8^{\text {th }}$ hour and Table 6 shows the results of our survey.

\section{Table 6}

The amount of order under various scenarios at $8^{\text {th }}$ hour

\begin{tabular}{|c|c|c|c|c|c|c|c|c|}
\hline Part & Minimum inventory & Order point & Production & Available parts & Demand & The order pallet & Order quantity & Need \\
\hline 1 & 60 & 92 & 92 & 125 & 184 & 59 & 59 & YES \\
\hline 2 & 60 & 92 & 92 & 125 & 184 & 59 & 59 & YES \\
\hline 3 & 60 & 92 & 92 & 126 & 184 & 58 & 58 & YES \\
\hline \multicolumn{9}{|c|}{ The second scenario: The amount of order of a complete shift at $8^{\text {th }}$ hour when the amount of inventory exceeds demand } \\
\hline Part & Minimum inventory & Order point & Production & Available parts & Demand & The order pallet & Order quantity & Need \\
\hline 1 & 60 & 92 & 240 & 125 & 332 & 207 & 207 & YES \\
\hline 2 & 60 & 92 & 240 & 125 & 332 & 207 & 207 & YES \\
\hline 3 & 60 & 92 & 240 & 126 & 332 & 206 & 206 & YES \\
\hline \multicolumn{9}{|c|}{ The third scenario: The amount of order until the receipt of the next shipment at $8^{\text {th }}$ hour when the order is placed at $4^{\text {th }}$ hour } \\
\hline Part & Minimum inventory & Order point & Production & Available parts & Demand & The order pallet & Order quantity & Need \\
\hline 1 & 60 & 92 & 92 & 240 & 184 & 0 & 0 & $\mathrm{NO}$ \\
\hline 2 & 60 & 92 & 92 & 240 & 184 & 0 & 0 & NO \\
\hline 3 & 60 & 92 & 92 & 240 & 184 & 0 & 0 & NO \\
\hline \multicolumn{9}{|c|}{ The fourth scenario: The amount of order until the receipt of complete shift requirements at $8^{\text {th }}$ hour when the order is placed at $4^{\text {th }}$ hour } \\
\hline Part & Minimum inventory & Order point & Production & Available parts & Demand & The order pallet & Order quantity & Need \\
\hline 1 & 60 & 92 & 240 & 240 & 332 & 92 & 92 & YES \\
\hline 2 & 60 & 92 & 240 & 240 & 332 & 92 & 92 & YES \\
\hline 3 & 60 & 92 & 240 & 240 & 332 & 92 & 92 & YES \\
\hline \multicolumn{9}{|c|}{ The fifth scenario: The amount of order until the receipt of an order at $8^{\text {th }}$ hour when the order is placed at $6^{\text {th }}$ hour } \\
\hline Part & Minimum inventory & Order point & Production & Available parts & Demand & The order pallet & Order quantity & Need \\
\hline 1 & 60 & 92 & 92 & 135 & 184 & 49 & 49 & YES \\
\hline 2 & 60 & 92 & 92 & 135 & 184 & 49 & 49 & YES \\
\hline 3 & 60 & 92 & 92 & 136 & 184 & 48 & 48 & YES \\
\hline \multicolumn{9}{|c|}{ The sixth scenario: The amount of order until the receipt of complete shift requirements at $8^{\text {th }}$ hour when the order is placed at $6^{\text {th }}$ hour } \\
\hline Part & Minimum inventory & Order point & Production & Available parts & Demand & The order pallet & Order quantity & Need \\
\hline 1 & 60 & 92 & 240 & 135 & 332 & 197 & 197 & YES \\
\hline 2 & 60 & 92 & 240 & 135 & 332 & 197 & 197 & YES \\
\hline 3 & 60 & 92 & 240 & 136 & 332 & 196 & 196 & YES \\
\hline
\end{tabular}




\section{The Simulation}

We now present details of the simulation under five different scenarios. In the first scenario, the chair of the workstation makes the orders manually by visiting the plants. Any shortage in order quantity may create different chaos in planning. Fig. 1 demonstrates the summary of our simulation process.

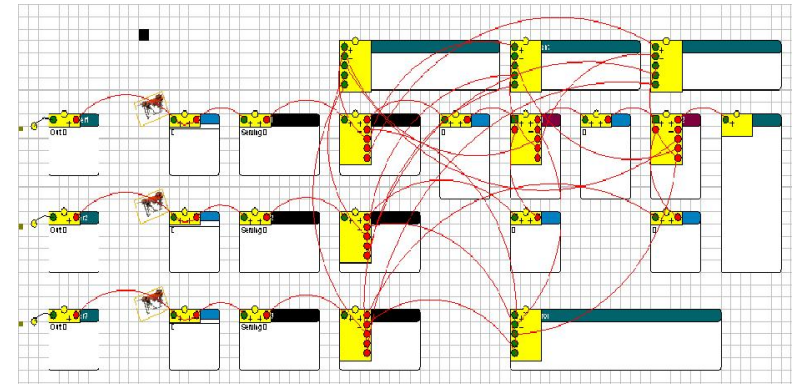

Fig. 1. The results of simulation for the first scenario

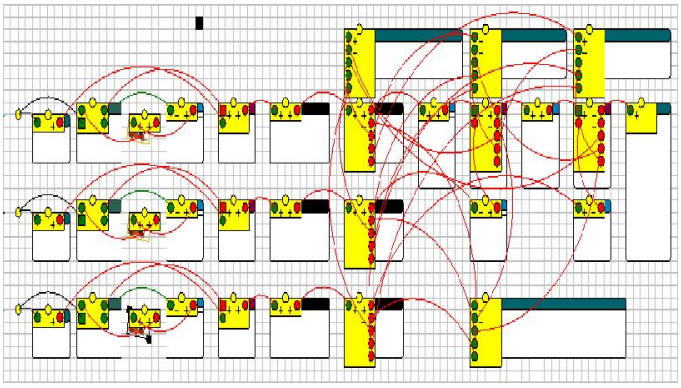

Fig. 2. The results of simulation for the second scenario

In the second scenario, we plan to assign a RFID to each pallet. Therefore, when the pallet becomes empty, the driver of lift trucks or an inspector could understand about the new circumstance and fill in the pallet. Note that when there is only one empty pallet in the system, there is a chance of facing shortage. In the third scenario, we consider a separate label for each part and we could keep track of the number of parts in each pallet (Fig. 3). In the fourth scenario, we save more information about the position of parts located in various pallets (Fig. 4).

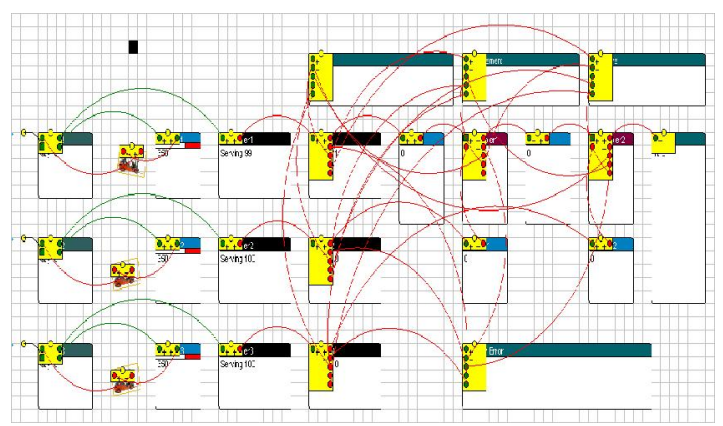

Fig. 3. The results of simulation for the third scenario

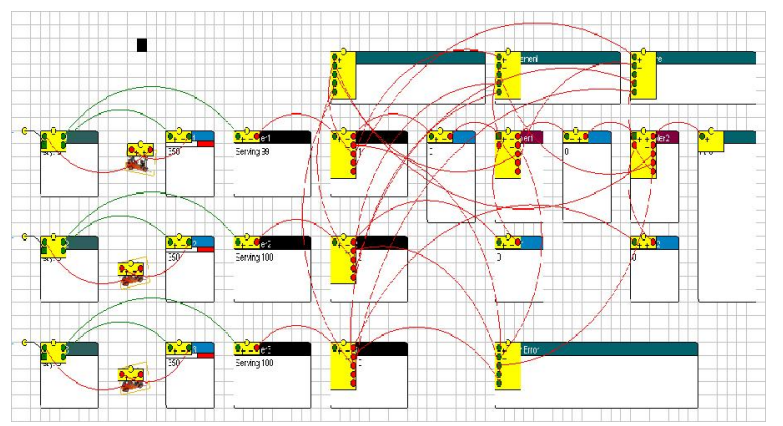

Fig. 4. The results of simulation for the fourth scenario

Table 7, Table 8 and Table 9 demonstrate the summary of our simulation for the first part for five scenarios.

Table 7

The summary of the simulation of the first product for five scenarios

\begin{tabular}{lccccc}
\hline & 1 & 2 & 3 & 4 & 5 \\
\hline Output (\%) & 85.71 & 89.64 & 94.29 & 94.29 & 94.29 \\
Stolen part (\%) & 0.57 & 0.40 & 0.29 & 0.29 & 0.29 \\
Replaced by mistake (\%) & 4.57 & 1.99 & 0.86 & 0.86 & 0.86 \\
Error in delivery (\%) & 3.71 & 3.19 & 1.43 & 1.43 & 1.43 \\
\hline Unavailable (\%) & 5.43 & 5.18 & 3.14 & 3.14 & 3.14 \\
\hline
\end{tabular}


Table 8

The summary of the simulation of the second product for five scenarios

\begin{tabular}{lccccc}
\hline & 1 & 2 & 3 & 4 & 5 \\
\hline Output (\%) & 87.14 & 90.44 & 94.86 & 94.86 & 94.86 \\
Stolen part (\%) & 0.57 & 0.40 & 0.29 & 0.29 & 0.29 \\
Replaced by mistake (\%) & 4.86 & 2.39 & 0.86 & 0.86 & 0.86 \\
Error in delivery (\%) & 4.29 & 3.59 & 1.14 & 1.14 & 1.14 \\
\hline Unavailable (\%) & 3.14 & 3.19 & 2.86 & 2.86 & 2.86 \\
\hline
\end{tabular}

Table 9

The summary of the simulation of the third product for five scenarios

\begin{tabular}{lccccc}
\hline & 1 & 2 & 3 & 4 & 5 \\
\hline Output (\%) & 85.43 & 89.24 & 94.29 & 94.29 & 94.29 \\
Stolen part (\%) & 0.57 & 0.40 & 0.29 & 0.29 & 0.29 \\
Replaced by mistake (\%) & 5.14 & 2.79 & 1.14 & 1.14 & 1.14 \\
\hline Error in delivery (\%) & 4.57 & 3.98 & 1.14 & 1.14 & 1.14 \\
Unavailable (\%) & 4.29 & 3.59 & 3.14 & 3.14 & 3.14 \\
\hline
\end{tabular}

We have measured the performance of the proposed model under various scenarios and Fig. 5 shows customer satisfaction in five different scenarios.

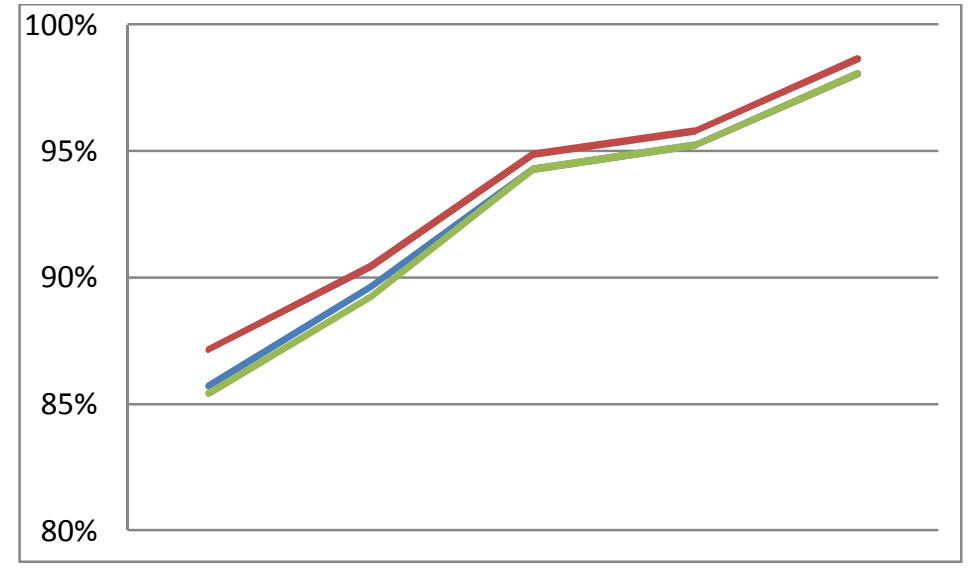

$\begin{array}{llllll}\text { Scenario } & 1 & 2 & 3 & 4 & 5\end{array}$

Fig. 5. The results of customer satisfaction in five scenarios

As we can observe from Fig. 5, customer satisfaction increases from the first scenario, present situation, to the fifth scenario. Fig. 6 demonstrates the error in measuring the inventory.

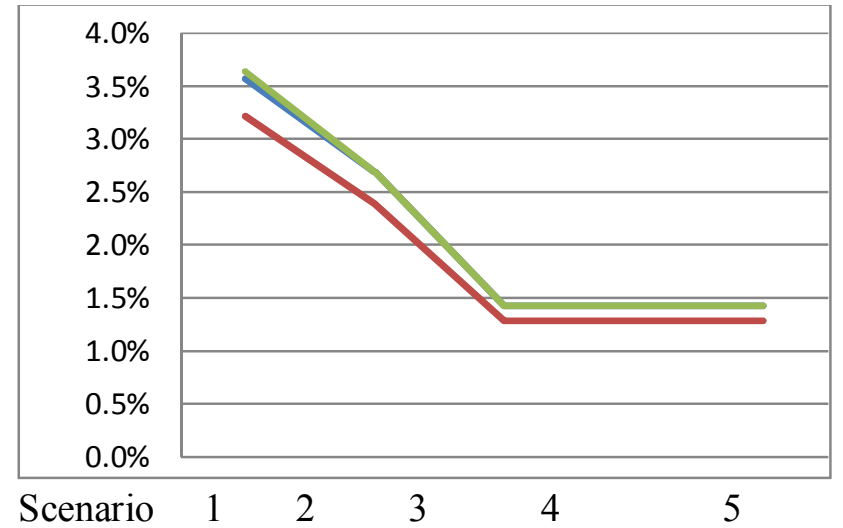

Fig. 6. Calculated error in inventory 
According to the results of Fig. 6, scenarios 4 and 5 could significantly reduce the error in measuring the inventory. Our survey also indicates that the performance of supply chain increases in the fourth and fifth scenarios while the profitability will relatively higher for the third scenario, see Fig. 7.

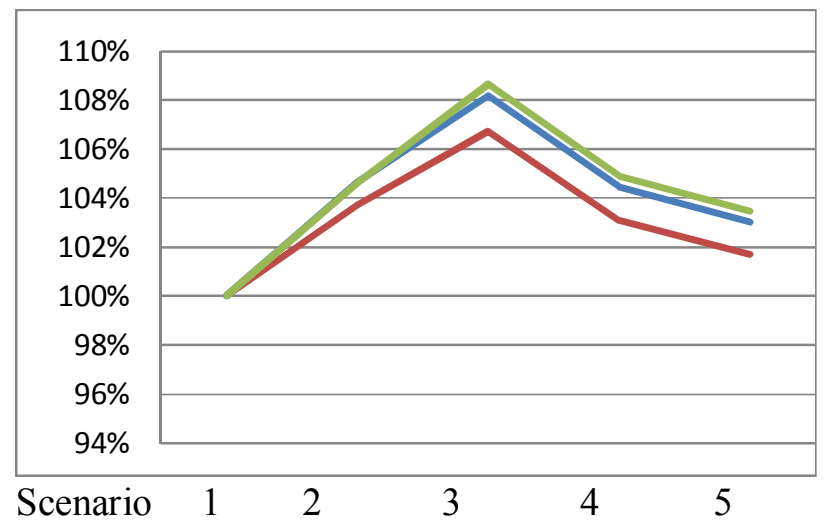

Fig. 7. The profitability

\section{Conclusion}

In this paper, we have presented an empirical investigation to study the behavior of a production planning by applying RFID system. The proposed study has considered the performance of the system under various types of RFID implementation and the behavior of the system has been examined using simulation technique. The results of our survey have indicated that we could increase the profitability of the system when we consider a separate label for each part and keep track of the number of parts in each pallet although other RFID implementation also improved the performance of the system, significantly.

\section{References}

Angeles, R. (2005). RFID technologies: supply-chain applications and implementation issues. Information Systems Management, 22(1), 51-65.

Asif, Z., \& Mandviwalla, M. (2005). Integrating the supply chain with RFID: a technical and business analysis. Communications of the Association for Information Systems, 15(24), 393-426.

Cannon, A. R., Reyes, P. M., Frazier, G. V., \& Prater, E. L. (2008). RFID in the contemporary supply chain: multiple perspectives on its benefits and risks. International Journal of Operations \& Production Management, 28(5), 433-454.

Gaukler, G. M., Seifert, R. W., \& Hausman, W. H. (2007). Item-Level RFID in the retail supply chain. Production and Operations Management, 16(1), 65-76.

Niederman, F., Mathieu, R. G., Morley, R., \& Kwon, I. W. (2007). Examining RFID applications in supply chain management. Communications of the ACM, 50(7), 92-101.

Prater, E., Frazier, G. V., \& Reyes, P. M. (2005). Future impacts of RFID on e-supply chains in grocery retailing. Supply Chain Management: An International Journal, 10(2), 134-142.

Veronneau, S., \& Roy, J. (2009). RFID benefits, costs, and possibilities: the economical analysis of RFID deployment in a cruise corporation global service supply chain. International Journal of Production Economics, 122(2), 692-702. 